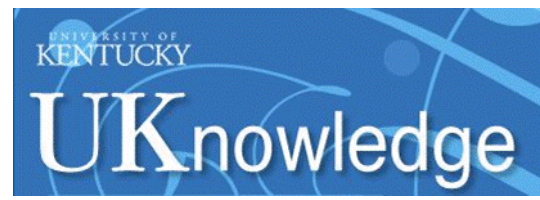

University of Kentucky

UKnowledge

$7-2014$

\title{
Correlation Between Microstructure and Thermionic Electron Emission from Os-Ru Thin Films on Dispenser Cathodes
}

\author{
Phillip D. Swartzentruber \\ University of Kentucky, pdswar2@uky.edu \\ Thomas John Balk \\ University of Kentucky, john.balk@uky.edu \\ Michael P. Effgen \\ Semicon Associates
}

Follow this and additional works at: https://uknowledge.uky.edu/cme_facpub

Part of the Chemical Engineering Commons, and the Materials Science and Engineering Commons Right click to open a feedback form in a new tab to let us know how this document benefits you.

\section{Repository Citation}

Swartzentruber, Phillip D.; Balk, Thomas John; and Effgen, Michael P., "Correlation Between Microstructure and Thermionic Electron Emission from Os-Ru Thin Films on Dispenser Cathodes" (2014). Chemical and Materials Engineering Faculty Publications. 9.

https://uknowledge.uky.edu/cme_facpub/9

This Article is brought to you for free and open access by the Chemical and Materials Engineering at UKnowledge. It has been accepted for inclusion in Chemical and Materials Engineering Faculty Publications by an authorized administrator of UKnowledge. For more information, please contact UKnowledge@lsv.uky.edu. 


\title{
Correlation Between Microstructure and Thermionic Electron Emission from Os- Ru Thin Films on Dispenser Cathodes
}

\author{
Digital Object Identifier (DOI) \\ http://dx.doi.org/10.1116/1.4876337 \\ Notes/Citation Information \\ Published in Journal of Vacuum Science \& Technology A, v. 32, no. 4, article 040601, p. 1-6.
}

Copyright 2014 AIP Publishing. This article may be downloaded for personal use only. Any other use requires prior permission of the author and the American Institute of Physics.

The following article appeared in Journal of Vacuum Science \& Technology A, v. 32, no. 4, article 040601, p. 1-6 and may be found at http://dx.doi.org/10.1116/1.4876337 


\title{
LETTERS
}

\section{Correlation between microstructure and thermionic electron emission from Os-Ru thin films on dispenser cathodes}

\author{
Phillip D. Swartzentruber and Thomas John Balk ${ }^{\text {a) }}$ \\ Department of Chemical and Materials Engineering, University of Kentucky, 177 F. Paul Anderson Tower, \\ Lexington, Kentucky 40506-0046 \\ Michael P. Effgen ${ }^{\text {b) }}$ \\ Semicon Associates, Lexington, Kentucky 40510
}

(Received 13 February 2014; accepted 2 May 2014; published 21 May 2014)

\begin{abstract}
Osmium-ruthenium films with different microstructures were deposited onto dispenser cathodes and subjected to $1000 \mathrm{~h}$ of close-spaced diode testing. Tailored microstructures were achieved by applying substrate biasing during deposition, and these were evaluated with scanning electron microscopy, $\mathrm{x}$-ray diffraction, and energy dispersive x-ray spectroscopy before and after close-spaced diode testing. Knee temperatures determined from the close-spaced diode test data were used to evaluate cathode performance. Cathodes with a large $\{10-11\}$ Os-Ru film texture possessed comparatively low knee temperatures. Furthermore, a low knee temperature correlated with a low effective work function as calculated from the close-spaced diode data. It is proposed that the formation of strong $\{10-11\}$ texture is responsible for the superior performance of the cathode with a multilayered Os-Ru coating. (c) 2014 American Vacuum Society. [http://dx.doi.org/10.1116/1.4876337]
\end{abstract}

\section{INTRODUCTION}

Osmium-ruthenium (Os-Ru) alloy thin films are utilized by the dispenser cathode industry to enhance electron emission properties. It was discovered by Zalm et al. that coating Os on a standard dispenser cathode (B-type) would result in a cathode with a lower effective work function. ${ }^{1}$ Zalm et al. studied other coatings that also yielded cathodes with lower effective work functions, but Os has proved to give the greatest reduction in work function. ${ }^{1}$ The Os coating was eventually replaced by an Os-Ru alloy coating due to concerns about possible formation of highly toxic $\mathrm{OsO}_{4}$. The Os-Ru alloy coating varies only negligibly from an Os coating in terms of effective work function reduction and its effect on cathode performance. ${ }^{2}$ Other refractory element coatings, such as osmium-iridium, have also been applied to dispenser cathodes in order to achieve properties similar to those of cathodes coated with Os-Ru. ${ }^{2}$ Dispenser cathodes with a top layer coating of a refractory metal are typically referred to as M-type dispenser cathodes.

Dispenser cathodes are essential components in devices that see service in space and military applications. As such, these devices require long lifetime and high reliability. There are two well accepted lifetime limiting factors for M-type dispenser cathodes: depletion of Ba from the impregnate and degradation of the coating. ${ }^{3-5}$ The impact of these factors is exacerbated at elevated temperature. The motivation behind the current study is to understand how the

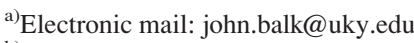

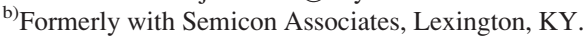

coating enhances electron emission and how it can be optimized to improve the lifetime of M-type dispenser cathodes.

The focus of many studies on M-type dispenser cathodes has been on chemical composition and barium adsorption/ desorption. $^{6-9}$ Additionally, the microstructure of the substrate material, $\mathrm{W}$ or a mixed-metal matrix, has been investigated. ${ }^{10-12}$ However, few studies have investigated the microstructure of the coating itself and how it relates to cathode performance. Liu et al. investigated a nanoparticle thin film coating of Ir and its effect on thermionic emission. It was found that the nanoparticle Ir thin film possessed similar emission capabilities to the traditional M-type cathode. However, no information on crystal structure or grain orientation was presented. ${ }^{13}$ Green et al. and Brion et al. studied Os-W coatings and the phases that developed in the coating during cathode operation. ${ }^{7,8}$ They found that the formation of a $\sigma$-phase alloy correlated with enhanced emission. Still, no crystallographic information was presented for the coatings that existed on the $\mathrm{W}$ substrates.

It is well known that the work function of a material varies for different crystallographic planes. In body-centered cubic W for example, the $\{100\},\{110\}$, and $\{111\}$ crystal faces have work functions of $4.63 \mathrm{eV}, 5.22 \mathrm{eV}$, and $4.45 \mathrm{eV}$, respectively. ${ }^{14}$ When considering the work function of crystalline materials, crystallographic information should be discussed in order to achieve a more complete understanding. As first shown by Zalm et al., for M-type cathodes a higher work function base metal coating correlates with a low work function cathode. ${ }^{1}$ This counterintuitive trend was explained on the basis of a model with $\mathrm{Ba}$ on $\mathrm{O}$ on metal, where $\mathrm{Ba}-\mathrm{O}$ acts as a dipole that reduces the barrier to electron emission, 
TABLE I. Deposition parameters and texture components of Os-Ru films.

\begin{tabular}{lccc}
\hline \hline Film type & $\begin{array}{c}\text { Thickness } \\
(\mathrm{nm})\end{array}$ & $\begin{array}{c}\text { Substrate } \\
\text { bias }(\mathrm{W})\end{array}$ & $\begin{array}{c}\text { Major as-deposited } \\
\text { texture component }\end{array}$ \\
\hline Multilayer & $25 / 150 / 25^{\mathrm{a}}$ & $20 / 5 / 0^{\mathrm{a}}$ & $\{10-11\}^{\mathrm{b}}$ \\
Semicon & 550 & 0 & $\{10-10\}$ \\
$5 \mathrm{~W}-550 \mathrm{~nm}$ & 550 & 5 & $\{0002\}$ \\
$10 \mathrm{~W}-150 \mathrm{~nm}$ & 150 & 10 & $\{10-11\}$ \\
\hline \hline
\end{tabular}

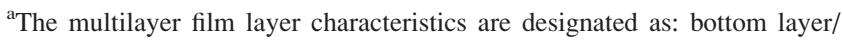
middle layer/top layer.

${ }^{\mathrm{b}}$ The predominant texture components of the individual layers, when deposited independently, are $\{10-10\} /\{0002\} /\{0002\}$. However, the $\{10-11\}$ texture is dominant in the overall composite film.

and where this effect is stronger for metals with higher work function. Additionally, Haas et al. and Cortenraad et al. pointed out that the crystallographic structure of the substrate surface should have a strong influence on the Ba-O dipole layer and therefore the overall work function of the cathode. ${ }^{15,16}$ Thus, while chemical composition, emission uniformity, and barium adsorption/desorption are important aspects to consider in M-type dispenser cathodes, the microstructure of the coating should also be considered but is often not discussed.

Previous studies have shown that the microstructure of Os-Ru thin films can be controlled through the use of substrate biasing and that the microstructure has an influence on the emission properties of M-type dispenser cathodes. ${ }^{17,18}$ However, the exact nature of the influence is not well understood. In this study, microstructural characterization was performed on the Os-Ru coatings of M-type cathodes operated for $1000 \mathrm{~h}$ in a close-spaced diode (CSD) setup. The microstructures of the Os-Ru films were characterized and then compared on the basis of knee temperature as determined from CSD testing.

\section{EXPERIMENT}

\section{A. Film preparation and characterization}

Based on the work by Li et al., ${ }^{17}$ Os-Ru thin films with engineered microstructures were deposited simultaneously onto dispenser cathodes and $\mathrm{W}$ pellets. The dispenser cathodes and $\mathrm{W}$ pellets were manufactured by Semicon Associates in Lexington, KY. Both the cathodes and the $\mathrm{W}$ pellets had a diameter of $3.11 \mathrm{~mm}$ and were nominally $16 \%$ porous. The Os-Ru films were deposited at the University of Kentucky using DC magnetron sputtering (ATC Orion system, AJA International Inc.), and substrate bias was applied at predetermined levels to produce specific microstructures. The base pressure of the sputtering system was $6.67 \times 10^{-6} \mathrm{~Pa}(5.0$ $\times 10^{-8}$ Torr) and the argon pressure during deposition was $0.33 \mathrm{~Pa}\left(2.5 \times 10^{-3}\right.$ Torr $)$. Table I summarizes the film deposition parameters and the corresponding microstructures.

The Os-Ru films were then studied with scanning electron microscopy (SEM, Hitachi S4300 and S900), x-ray diffraction (XRD, Siemens D500), and X-ray energy dispersive spectroscopy (EDS) to determine the resulting microstructure, texture, and composition of each film in the as-deposited state. After CSD testing, the cathodes were re-examined by SEM, XRD, and EDS to characterize any changes.

\section{B. Close-spaced diode testing}

Dispenser cathodes with different Os-Ru film microstructures were sent to eBeam, Inc., for CSD testing. To provide a baseline for comparison, a commercially available, Os-Ru M-type dispenser cathode from Semicon Associates was also
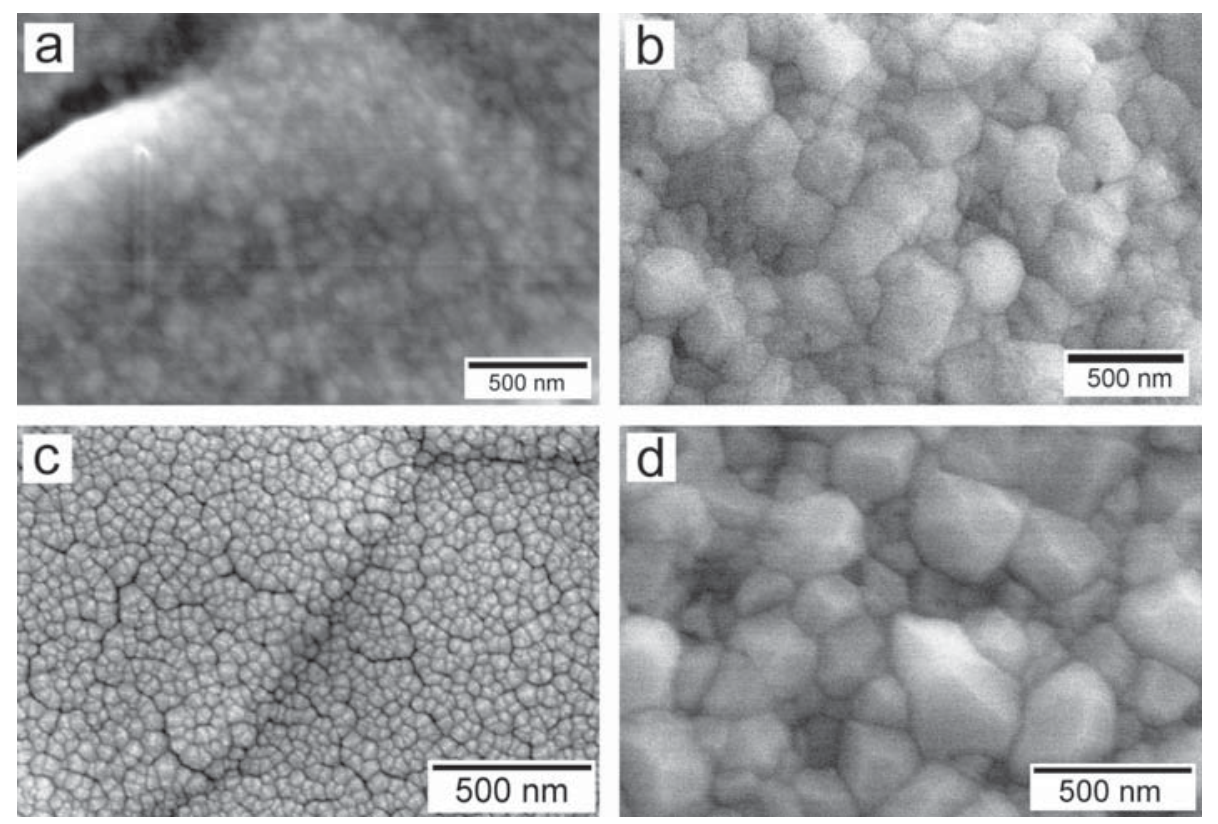

FIG. 1. SEM images showing grain growth of $10 \mathrm{~W}-150 \mathrm{~nm}[(\mathrm{a})$ and (b)] and Semicon [(c) and (d)] Os-Ru films after $1000 \mathrm{~h}$ in a CSD test. Images (a) and (c) show the films in their as-deposited states, while (b) and (d) show the films after $1000 \mathrm{~h}$ at elevated temperature. These images are representative of the grain growth seen in all samples after CSD testing. 
included in the same test vehicle sent to eBeam, Inc. (Note that Semicon Associates uses RF diode sputtering to deposit their films, with no substrate biasing.) The cathodes were aged at $1100{ }^{\circ} \mathrm{C}_{\mathrm{B}}$ (brightness temperature, which corresponds to a true temperature of $1171^{\circ} \mathrm{C}$ ) for $1000 \mathrm{~h}$. Data were collected just after the initial activation $(0 \mathrm{~h})$, at $500 \mathrm{~h}$, and at $1000 \mathrm{~h}$. At each measurement interval and for each cathode, the change in anode current with cathode temperature was recorded for four different voltages applied to the cathode. For subsequent calculations, all brightness temperatures were converted to true temperatures.

\section{RESULTS AND DISCUSSION}

In the as-deposited state, all films exhibited small grains on the order of 10-20 nm as evidenced from the SEM and seen in Figs. 1(a) and 1(c). After $1000 \mathrm{~h}$ of CSD testing, grain size increased significantly to approximately $100-200 \mathrm{~nm}$, as
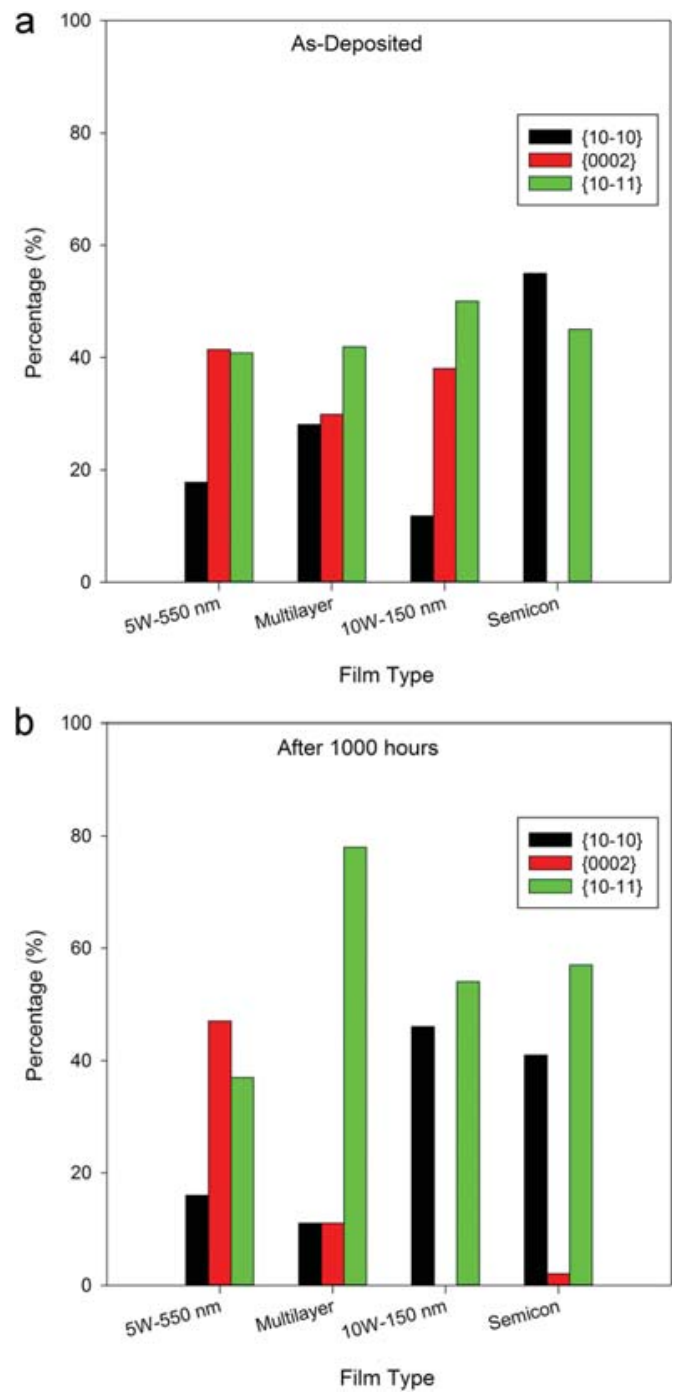

FIG. 2. (Color online) Texture components of Os-Ru films: (a) in the asdeposited state and (b) after $1000 \mathrm{~h}$ operation in close-spaced diode testing. The majority of the multilayer film texture components transformed into the $\{10-11\}$ component. Other films retained a mixture of significant secondary components. seen in Figs. 1(b) and 1(d). This growth highlighted the fact that significant atomic rearrangement occurred in the film. After characterizing the films with XRD it was found that some films had experienced a substantial change in film texture as well. Figure 2 compares the texture components in each film and demonstrates a clear difference in film texture. While the $5 \mathrm{~W}-550 \mathrm{~nm}$ film maintained its primarily basal texture, the multilayer, $10 \mathrm{~W}-150 \mathrm{~nm}$, and standard Semicon film all transformed to either a $\{10-11\}$ film texture or a mixed texture of $\{10-11\}$ and $\{10-10\}$. Figure 3 shows an XRD scan of the multilayer coated cathode before and after CSD testing (with texture transformation induced by the CSD test). The Os-Ru peaks in the as-deposited state are present, albeit at low intensity. The peaks are more easily seen after CSD testing, and there is a clear preference for $\{10-11\}$ orientation.

The CSD test data allowed determination of the knee temperature $\left(T_{\text {knee }}\right)$ for cathodes at various stages of testing. Figure 4 shows the anode current versus temperature for each cathode over the course of the $1000 \mathrm{~h}$ test. Table II summarizes the cathode knee temperatures at three intervals during the $1000 \mathrm{~h}$ test. The knee temperature is often used as a means to compare cathode performance. The knee temperature is the point, on a plot of anode current versus cathode temperature, where electron emission changes from space charge limited to temperature limited. Dispenser cathodes are often operated just above $T_{\text {knee }}$. The temperature-limited regime of electron emission from a hot body is governed by the well-known Richardson equation

$$
J=A T^{2} \exp \left(-\frac{\varphi}{k T}\right),
$$

where $J$ is the anode current density, $A$ is theoretically $120 \mathrm{~A} \cdot \mathrm{cm}^{-2} \cdot \mathrm{K}^{-2}, T$ is temperature, $\varphi$ is work function, and $k$ is the Boltzmann constant. Because temperature-limited emission rises exponentially with temperature, the high temperature portion of the curve can be taken as linear. Ideally,

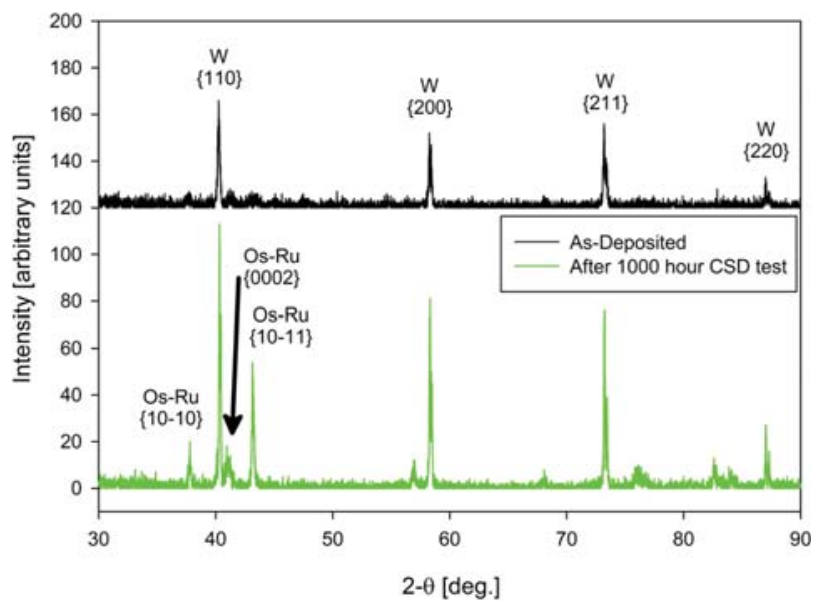

FIG. 3. (Color online) X-ray diffraction scans of the multilayer coated cathode before (top) and after (bottom) $1000 \mathrm{~h}$ of CSD testing. The tungsten substrate and Os-Ru peaks are indicated in the figure. The smaller peaks that appear in the bottom scan correspond to higher-index Os-Ru planes. 
a

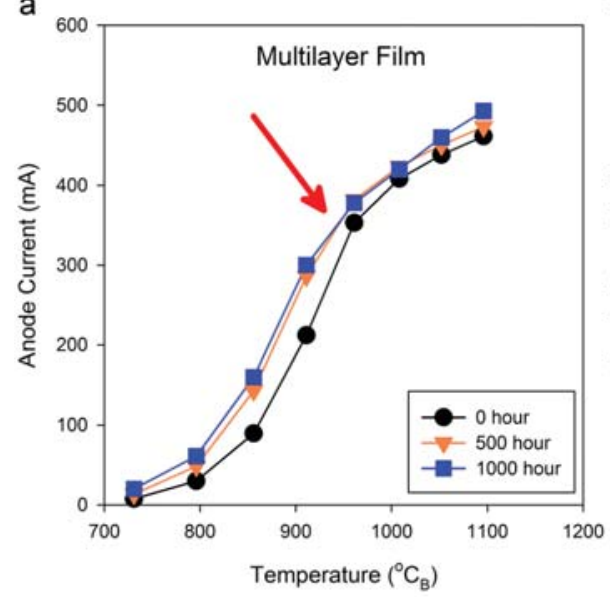

c

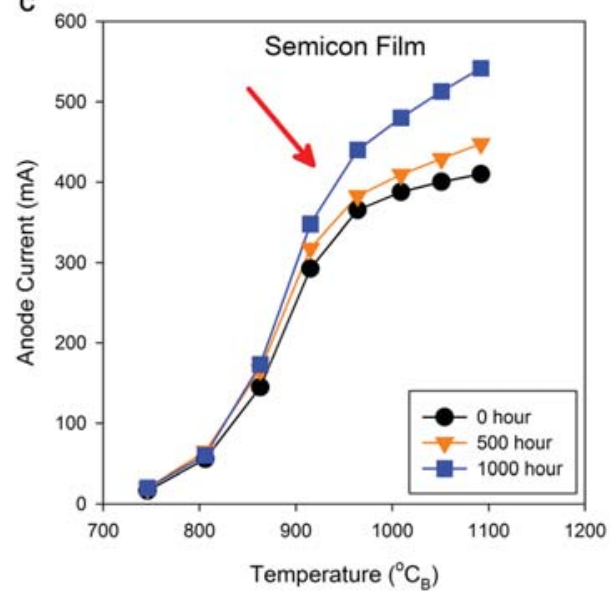

b

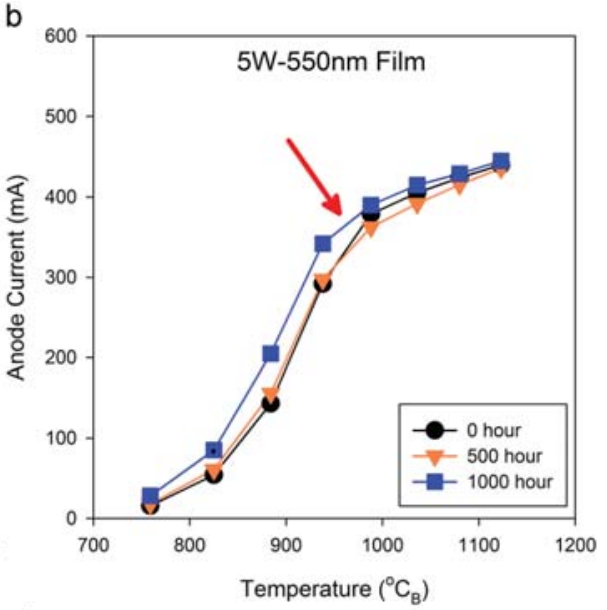

d

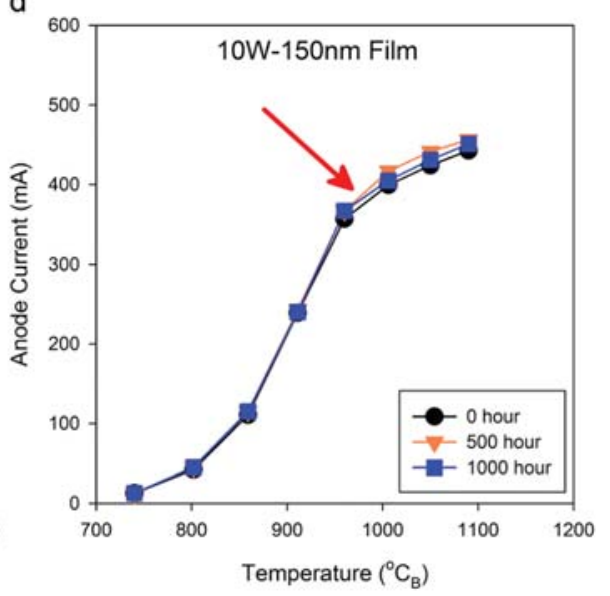

FIG. 4. (Color online) Current vs temperature plots for the (a) multilayer, (b) $5 \mathrm{~W}-550 \mathrm{~nm}$, (c) Semicon, and (d) $10 \mathrm{~W}-150 \mathrm{~nm}$ cathodes after 0 , 500 , and 1000 $\mathrm{h}$ of aging. The knee temperature $T_{\text {knee }}$ (indicated by an arrow) for each cathode was extracted from these plots by fitting lines to the linear portions of the temperature limited and space charge limited regions and taking their intersection point as $T_{\mathrm{knee}}$. The accelerating voltage was $235 \mathrm{~V}, 230 \mathrm{~V}, 190 \mathrm{~V}$, and $170 \mathrm{~V}$ for the multilayer film, Semicon film, $5 \mathrm{~W}-550 \mathrm{~nm}$ film, and $10 \mathrm{~W}-150 \mathrm{~nm}$, respectively, after $1000 \mathrm{~h}$.

the space charge limited region manifests itself as a plateau in current on a plot of anode current versus temperature. However, the transition from temperature limited to space charge limited is typically not sharp and occurs over a range of temperatures. This is typically attributed to a work function distribution on the surface of the cathode. ${ }^{19}$ Therefore, the space charge limited region on a plot of anode current versus temperature is typically represented as a line with a small positive slope. If lines are fitted to the space charge limited region and the linear portion of the temperature

TABLE II. Cathode knee temperatures over $1000 \mathrm{~h}$ and associated texture components.

\begin{tabular}{lcccc}
\hline \hline & \multicolumn{3}{c}{$T_{\text {knee }}\left({ }^{\circ} \mathrm{C}_{\mathrm{B}}\right)$} & \\
\cline { 2 - 4 } Cathode coating & $0 \mathrm{~h}$ & $500 \mathrm{~h}$ & $1000 \mathrm{~h}$ & Major texture components at $1000 \mathrm{~h}$ \\
\hline Multilayer & 976 & 946 & 934 & $\{10-11\}$ \\
Semicon & 940 & 930 & 940 & $\{10-11\}$ \\
$5 \mathrm{~W}-550 \mathrm{~nm}$ & 969 & 961 & 952 & $\{0002\}$ \\
$10 \mathrm{~W}-150 \mathrm{~nm}$ & 975 & 969 & 965 & $\{10-11\}$ \\
\hline \hline
\end{tabular}

limited region, the intersection point can be taken as the knee temperature.

Table II indicates that for a given cathode, $T_{\mathrm{knee}}$ either steadily improved over time or stayed relatively constant. The multilayer coated cathode displayed a significant improvement in $T_{\text {knee }}$ after $1000 \mathrm{~h}$, while the $10 \mathrm{~W}-150 \mathrm{~nm}$ coated and standard Semicon coated cathodes maintained fairly stable values of $T_{\text {knee }}$ from start to finish. The $5 \mathrm{~W}-550 \mathrm{~nm}$ coated cathode showed some improvement in $T_{\text {knee }}$ but not to the same extent as the multilayer coated cathode.

Along with the significant improvement in $T_{\text {knee }}$ for the multilayer coated cathode, film texture transformed from a mixture of $\{0002\},\{10-11\}$, and $\{10-10\}$ components, to a strong $\{10-11\}$ texture. The transformation of the basal component into other components cannot be the sole source of the improvements, since the $10 \mathrm{~W}-150 \mathrm{~nm}$ film lost all of its basal component and yet retained a high $T_{\text {knee }}$. Therefore, it is proposed that the creation of the $\{10-11\}$ texture component is responsible for the marked improvement in knee temperature. Other higher-index texture components were evaluated from XRD scans of all samples, and it is noted that the multilayer coated sample exhibited the lowest 
number and proportion of higher-index grain orientations. The multilayer coated cathode had the highest proportion of $\{10-11\}$ grains, suggesting that the strength of this texture (or lack of other texture components) contributed to the improvement in cathode performance.

To further evaluate cathode performance, the Richardson work function and the effective work function were extracted from CSD test data. The modified Richardson equation accounts for Schottky emission by replacing $\varphi$ with $(\varphi-\Delta \varphi)$, which reflects the change in work function due to applied electric field and is proportional to $V^{1 / 2}$. Therefore, a plot of $\log (J)$ versus $V^{1 / 2}$ at different temperatures for each cathode was constructed, from which the zero-field current density could be found through extrapolation. The zero-field current densities were then used to construct Richardson plots of $\log \left(J / T^{2}\right)$ versus $1 / k \cdot T$ and the slope of the resultant line taken as the Richardson work function. The effective work function simply calculates the work function using Eq. (1) and data from temperature limited emission. Here, the knee temperature and the associated emission current were used to calculate an effective work function. Table III summarizes the calculated work functions of the cathodes coated with different Os-Ru microstructures and their associated knee temperatures. The multilayer cathode has a significantly lower Richardson work function $(1.16 \mathrm{eV}$ at $1000 \mathrm{~h})$ than any of the other cathodes, while the $10 \mathrm{~W}-150 \mathrm{~nm}$ coated cathode has the highest at $1.72 \mathrm{eV}$. The effective work function and $T_{\text {knee }}$ correlate well, and therefore, the correlation of film texture with $T_{\text {knee }}$ also extends to work function. The correlation appears to be significantly non-linear for the lowest work function cathode. Richardson work function values are lower than expected. As seen in Table III, the effective work function values appear much more reasonable when compared to typical reported values for dispenser cathodes. The Semicon M-type Os-Ru coated cathodes have a reported work function of $1.8 \mathrm{eV}$. The Richardson work function calculated here is significantly lower than the reported value and could be due to errors inherent in the CSD test method, e.g., Ba resupply and geometric nonuniformities between the cathode and anode, which are exacerbated at high temperatures. The effective work function calculated using the knee temperature should represent some average of the work function distribution, since it uses a temperature and emission current from the transition region between temperature limited and space charge limited regimes. Therefore, if there were a strong bimodal work function distribution, the transition regions in CSD test curves and the effective work function calculated

TABLE III. Comparison of knee temperature, calculated work function, and associated parameters for CSD test cathodes.

\begin{tabular}{lcccc}
\hline \hline $\begin{array}{l}\text { Cathode } \\
\text { coating }\end{array}$ & $\begin{array}{l}T_{\text {knee }} \\
\left({ }^{\circ} \mathrm{C}_{\mathrm{B}}\right)\end{array}$ & $\begin{array}{c}\text { Richardson } \\
\text { work function }(\mathrm{eV})\end{array}$ & $\begin{array}{c}A_{\mathrm{R}} \\
\left(\mathrm{A} \cdot \mathrm{cm}^{-2} \cdot \mathrm{K}^{-1}\right)\end{array}$ & $\begin{array}{c}\text { Effective } \\
\text { work function }(\mathrm{eV})\end{array}$ \\
\hline Multilayer & 934 & 1.16 & 0.054 & 1.90 \\
Semicon & 940 & 1.42 & 1.382 & 1.90 \\
$5 \mathrm{~W}-550 \mathrm{~nm}$ & 952 & 1.61 & 5.321 & 1.93 \\
$10 \mathrm{~W}-150 \mathrm{~nm}$ & 965 & 1.72 & 13.473 & 1.95 \\
\hline \hline
\end{tabular}

from these curves would better reflect this distribution. The fact that the effective work functions correspond more closely with typical values reported for M-type cathodes suggests that there are work function distributions present. Nonetheless, the correlation of work function with $\{10-11\}$ remains.

The correlation of the development of $\{10-11\}$ texture with decreasing $T_{\text {knee }}$ and work function could be related to the nature of the $\{10-11\}$ plane in the HCP crystal structure. The difference in work function between crystal planes is usually attributed to planar density. Crystallographic orientations with low planar densities typically have low work functions. Orientations with higher planar densities will typically possess higher work functions. The work functions of crystal planes for HCP metals are not well characterized. However, available literature does show that the work functions of different HCP crystal planes do indeed differ. In rhenium, for example, the work function for the $\{0001\},\{10-10\}$, and $\{10-11\}$ planes are $5.59 \mathrm{eV}, 5.37 \mathrm{eV}$, and $5.15 \mathrm{eV}$ respectively. ${ }^{20}$ The $\{10-11\}$ plane has a relatively low planar density $(0.44$ in $\mathrm{Os}-\mathrm{Ru})$, and therefore a comparatively low work function. The low work function of the $\{10-11\}$ plane could correlate with the low effective work function of the multilayer coated cathode, since that coating has a strong $\{10-11\}$ texture. Furthermore, it could also explain why some of the cathodes steadily decrease their $T_{\text {knee, }}$ as microstructural changes are typically not instantaneous.

The Semicon film and the $5 \mathrm{~W}-550 \mathrm{~nm}$ film had similar thicknesses and resulted in fairly stable values of $T_{\text {knee}}$. Additionally, the $10 \mathrm{~W}-150 \mathrm{~nm}$ film had a similar thickness to the multilayer film yet showed little change in $T_{\text {knee }}$. This indicates that there may be some critical thickness or texture -or possibly a combination of both-that does not allow for marked emission improvement over time. Li et al. found that $5 \mathrm{~W}$ biased films were quite stable, but the reason for this stability could be due to a combination of aspects such as texture and thickness, or film density. ${ }^{11}$

Much of the available literature on work function cites values that were obtained indirectly, using cathode emission test data. Directly measuring the work function of a dispenser cathode would provide valuable insight into the nature of the activated surface without the numerous sources of error associated with calculating the effective work function from CSD tests. True work function measurement coupled with CSD test data would allow for more complete evaluation of dispenser cathode performance.

\section{SUMMARY AND CONCLUSIONS}

One thousand hours of operation in a CSD test setup revealed that the microstructures of Os-Ru films undergo significant changes. There is a marked increase in grain size and a shift in texture that favors $\{10-10\}$ and $\{10-11\}$ texture components for films with low knee-temperatures. There appears to be a correlation between $\mathrm{Os}-\mathrm{Ru}$ film texture and thermionic electron emission. It is proposed that formation of $\{10-11\}$ texture results in improved cathode performance. Values for effective work function were calculated from the CSD data and were found to correlate with knee 
temperature. However, the magnitudes were lower than what would normally be expected, based on values for the reference cathode. Direct measurement of work function could provide a more complete measure of electron emission from dispenser cathodes.

\section{ACKNOWLEDGMENTS}

This material is based upon work supported by the National Science Foundation under Grant No. CMMI0928845. Early results of this project were supported by a grant from the Kentucky Science and Engineering Foundation as per Grant Agreement KSEF-148-502-07-223 with the Kentucky Science and Technology Corporation. The authors would like to thank Semicon Associates for their helpful discussions and for supplying cathodes for testing. The authors would also like to acknowledge B. Vancil and eBeam, Inc., for the close-spaced diode tests.

${ }^{1}$ P. Zalm and A. J. A. v. Stratum, Philips Tech. Rev. 27, 69 (1966).

${ }^{2}$ J. L. Cronin, IEE Proc.-I 128, 19 (1981).

${ }^{3}$ J. M. Roquais, F. Poret, R. le Doze, J. L. Ricaud, A. Monterrin, and A. Steinbrunn, Appl. Surf. Sci. 215, 5 (2003).

${ }^{4}$ N. Mita, IEEE Trans. Electron. Devices 38, 2554 (1991).
${ }^{5}$ T. Higuchi, O. Nakamura, S. Matsumoto, and E. Uda, Appl. Surf. Sci. 146, 51 (1999).

${ }^{6}$ S. Kimura, D. Miyazaki, M. Hara, and M. Fujiwara, Vacuum 41, 1763 (1990).

${ }^{7}$ D. Brion, J. C. Tonnerre, and A. Shroff, Appl. Surf. Sci. 20, 429 (1985).

${ }^{8}$ M. C. Green, H. B. Skinner, and R. A. Tuck, Appl. Surf. Sci. 8, 13 (1981).

${ }^{9}$ A. P. Makarov and O. K. Kultashev, Appl. Surf. Sci. 111, 56 (1997).

${ }^{10}$ K. Santhosh Kumar, P. Durga Devi, M. Ravi, and K. S. Bhat, Appl. Surf. Sci. 252, 5632 (2006).

${ }^{11}$ B. K. Vancil, R. A. Mueller, E. R. Steele, W. L. Ohlinger, and E. G. Wintucky, Appl. Surf. Sci. 146, 39 (1999).

${ }^{12}$ J. S. Wang, L. L. Li, W. Liu, Y. C. Wang, L. Zhao, and Y. M. Wang, J. Phys. Chem. Solids 68, 2209 (2007).

${ }^{13}$ Y. W. Liu, H. Tian, Y. Han, P. K. Liu, and Y. X. Lu, IEEE Trans. Electron. Devices 59, 3618 (2012).

${ }^{14}$ D. R. Lide, CRC Handbook of Chemistry and Physics, 85 th ed. (Taylor \& Francis, Boca Raton, FL, 2004), pp. 12-130.

${ }^{15}$ G. A. Haas, A. Shih, D. Mueller, and R. E. Thomas, Appl. Surf. Sci. 59, 227 (1992).

${ }^{16}$ R. Cortenraad, A. W. D. v. d. Gon, H. H. Brongersma, G. Gärtner, and A. Manenschijn, Appl. Surf. Sci. 191, 153 (2002).

${ }^{17}$ W. C. Li, S. Roberts, and T. J. Balk, IEEE Trans. Electron. Devices 56, 805 (2009).

${ }^{18}$ P. Swartzentruber, T. J. Balk, S. Roberts, and M. Effgen, Proceedings of the 2012 IEEE 13th International Vacuum Electronics Conference (IVEC), Monterey, CA, 2012, pp. 163-164.

${ }^{19}$ J. C. Tonnerre, D. Brion, P. Palluel, and A. M. Shroff, Appl. Surf. Sci. 16, 238 (1983).

${ }^{20}$ J. Robichaud and F. E. Girouard, Can. J. Phys. 58, 43 (1980). 